\title{
Home Automation and Security using Raspberry Pi and Whatsapp
}

\author{
Pamarthi Kanakaraja, B. Srikanth Deepak, K. V. Jaya Nikhil, Y. V. S Pavan Rakesh, \\ K. Naga Venkatesh
}

\begin{abstract}
This paper presents an ingenious remotely sensible system that controls the home appliances by using WhatsApp. This is an IOT based model designed and developed by using Raspberry $\mathrm{Pi}-3$. In this proposed system of home automation, the feasibility of executing certain important tasks with higher controllability and remote access have been incorporated. Home appliances such as lights, fans, air conditioners, power driven electrical and electronic commodities etc., are made to control from any part of this world, using a mobile phone with WhatsApp installed in it. For ensuring this functionality, a web interface has been developed using the Raspberry $\mathrm{Pi}$, as a web server for operating and controlling the home appliances through any Wi-Fi accessible mobile device with WhatsApp feature.
\end{abstract}

Index terms: Dht11sensor, Mobilephone,Pirsensor, Raspberry pi, ThingSpeak, WhatsApp

\section{INTRODUCTION}

Now-a-days, automation has become prevalent and predominant in various environments. In general,the automation techniques are conventionally implemented either byusing microcontroller or a computer. Taking in to consideration of the throughputs and the efficiencies of Microcontrollers, it is quite understandable that, microcontrollers alone cannot handle the automation processes by runningmultiple programs simultaneously with appreciable speeds. Also, it is difficult to handle both the appliances and surveillance at a stretch. Keeping in view of the above crises, the optimum alternative has been the Raspberry $\mathrm{Pi}$ for implementing the automation of home appliances along with surveillance, based on its reliability. Several varieties of works have been proposed in the recent past regarding the automation of home appliances. A few are, [1] VineetPratap Singh has worked on facebook based home appliances security control and monitoring using Raspberry Pi-3 for controlling the home appliances through facebook (May 2017).

Revised Manuscript Received on December 30, 2019.

* Correspondence Author

P. Kanakaraja, Department of ECE, KoneruLakshmaiah Education Foundation, Vaddeswaram,.A.P,India

B. Srikanth Deepak, Department of ECE, KoneruLakshmaiah Education Foundation, Vaddeswaram A.P, India.

K. V. Jaya Nikhil, Department of ECE, KoneruLakshmaiah Education Foundation, Vaddeswaram, A.P,India

Y. V. S Pavan Rakesh, Department of ECE, KoneruLakshmaiah Education Foundation, Vaddeswaram, A.P,India.

K. Naga Venkatesh, Department of ECE, KoneruLakshmaiah Education Foundation, Vaddeswaram, A.P,India.

(c) The Authors. Published by Blue Eyes Intelligence Engineering and Sciences Publication (BEIESP). This is an open access article under the CC BY-NC-ND license (http://creativecommons.org/licenses/by-nc-nd/4.0/)
[2] M. P. Sathish has published home automation through e-mail using Raspberry Pi saying that e-mail can be used as a media to control the home appliances remotely (September 2015).

In this proposed work, the Raspberry Pi-3 Model B has been interfaced to WhatsApp application using yowsup libraries and hence the home appliances are made to control remotely through mobile phone installed with WhatsApp. This collaboration of WhatsApp and Raspberry Pi-3 has produced an exotic set of results and it is relatively secured when compared to social networking sites like facebook.

The Raspberry Piis a single board computer which contains GPIO and USB ports. Using these ports,the appliances can be efficiently controlled and the appropriate judgments for tuning the functionalities of thedevicescan be made with the help of sensors andcameras. Raspberry Pi can be used for multiple purposes, based on the requirement.

\section{METHODOLOGY}

This paper explains about the controlling of home appliances through WhatsApp by using communication protocol interfaces with Raspberry $\mathrm{Pi}$ as the processing unit. The server interfaced with the help of relay board, controls the functionality of the appliances. Raspberry Pi-3 is loaded with a SIM card, as well as a memory card, for the purposes of communication and data storage respectively. Followed by,the WhatsApp libraries (yowsup) are installedin Raspberry Pi-3 for establishing a link through WhatsApp. This enables the remote control of Raspberry Pi-3, where, commanding can be done from any part of the world to activate or deactivate the home appliances without physical presence at home. Hence, compactmessagessuch as "switch on fan", "switch on light", "switch off all" etc.,can be used for communicating the automation system from remote places through WhatsApp and so, the acknowledgements shall be received from Raspberry Pi-3, once the operation are performed based on the given commands. 


\section{RASPBERRY PIAND ITS SPECIFICATIONS:}

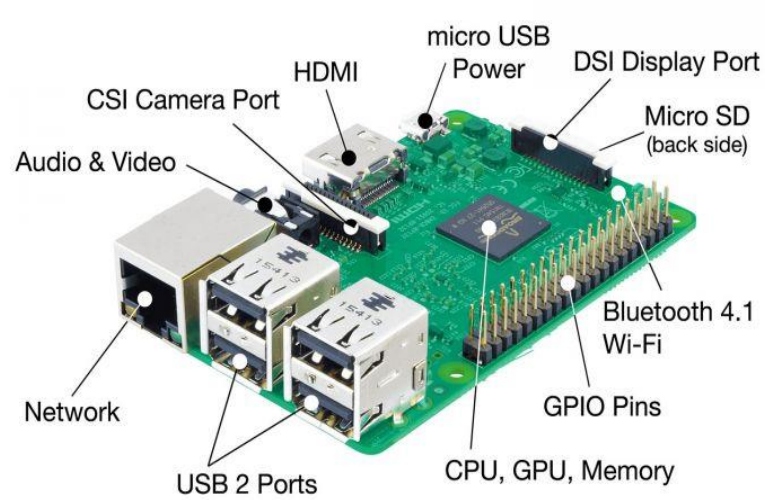

Source:

Fig.1: Raspberry Pi-3

https://www.silverlineelectronics.in/raspberry-pi-3-model-barmv8-with-1gb-ram.html

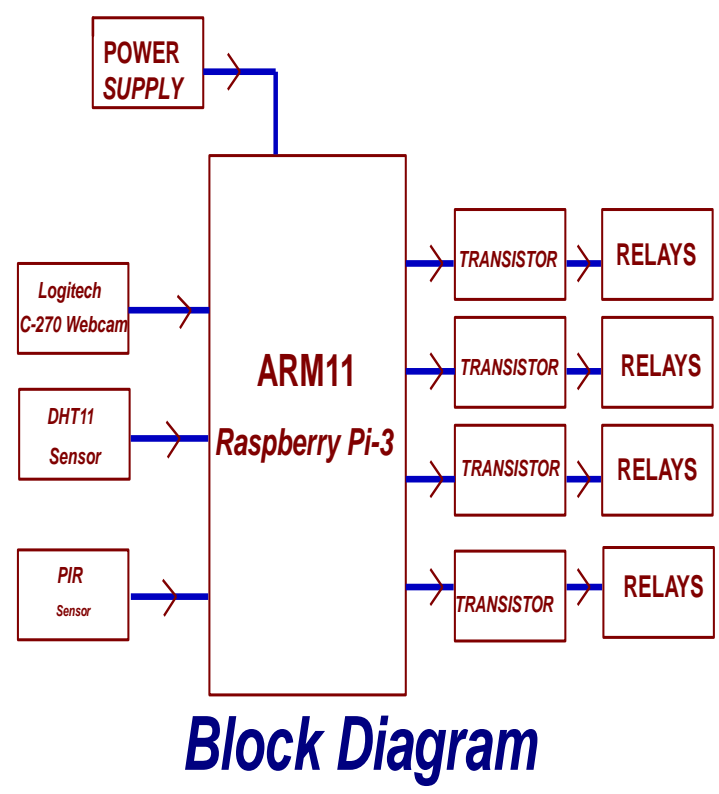

Fig.2: Fundamental steps of proposed system

Apart from the home appliances, DHT11 (temperature and humidity) sensor, PIR sensor and C270 web camera are interfaced to the ports of Raspberry Pi-3 for continuous monitoring and analysisof the surrounding conditions.DHT11 sensormeasures the temperature and humidity levels inside home and shall be reporting the automation system, if the temperature / humidity crosses a certainthreshold, for communicating the same to the remote user.The C270 web camera takes the snapshots of the room,if PIR sensor detects any movements of human beings /animals / objects,and sends them to the remote user's WhatsAppnumber, for getting recommended to take the appropriate actions. This can also be used in theindustries,for exploring and identifying any changes in the room temperatures in various critical chambers.Any sorts of abrupt changes can be reported on the spot to the remote user through WhatsApp and shall act as per the user's commands. This eliminates the damage of equipment in the industries and also lives at times.

\section{CIRCUIT DIAGRAM:}

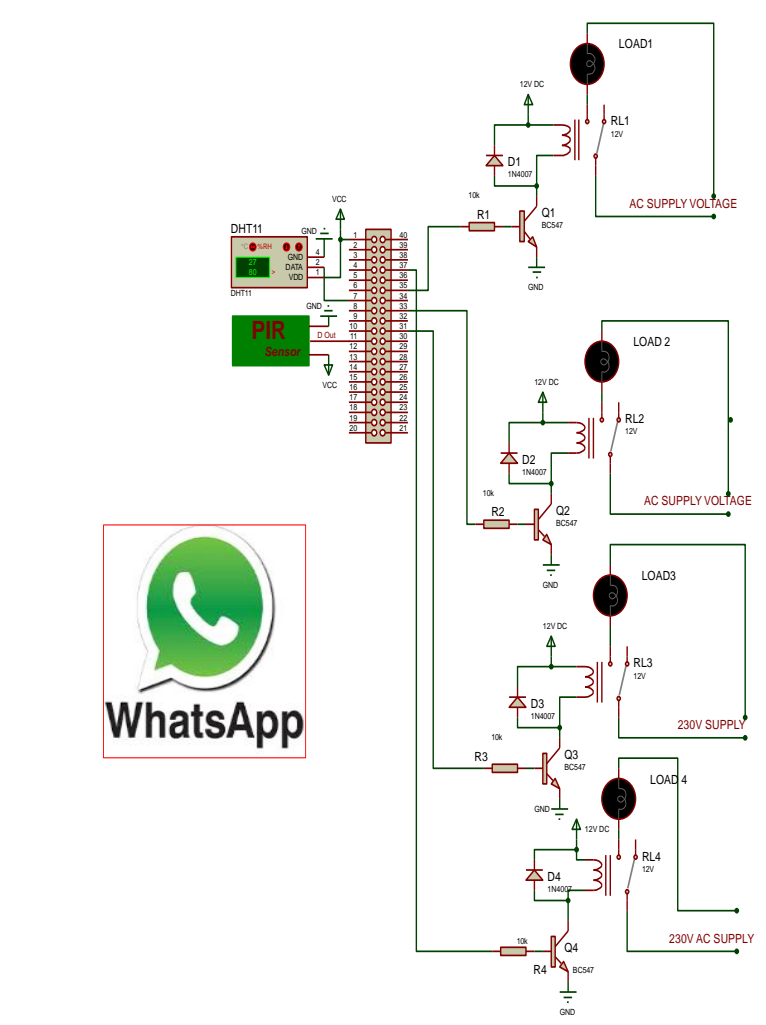

DHT11 Sensor:

Fig.3: Circuit Diagram.

Source:

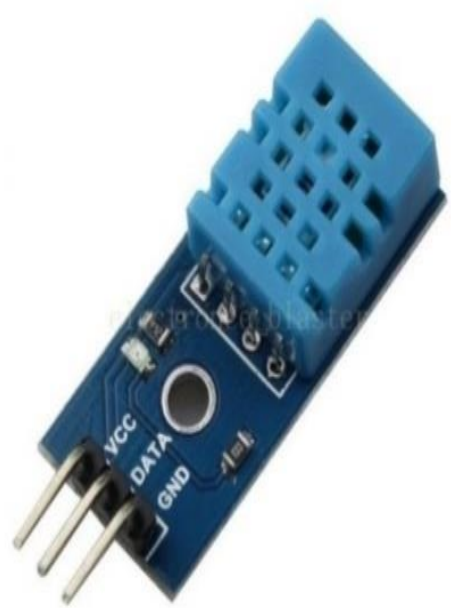

Fig.4: DHT11 Sensor

https://potentiallabs.com/cart/buy-dht11-sensor-module-onli ne-hyderabad-india

DHT11 Sensor is a digital temperature and humidity sensor. It is used to measure both temperature and humidity. It uses a Thermistor to measure the surrounding air and depicts humidity and temperature. For every 2 seconds the sensor changes the data and gives new data. It consumes $3.3 \mathrm{to} 5 \mathrm{v}$ of power.

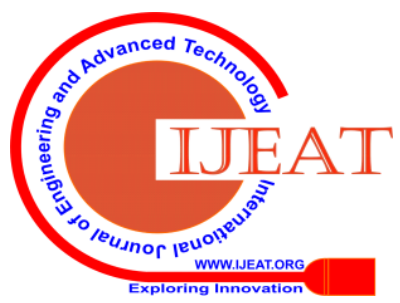


PIR Sensor:

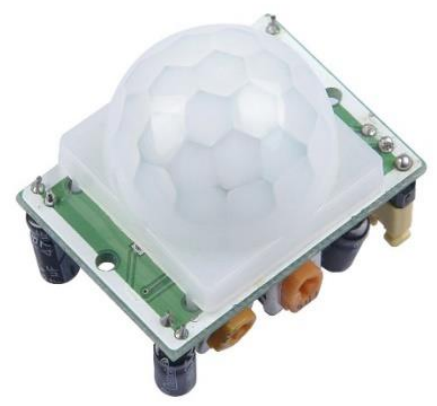

Fig.5: PIR Sensor

Source:https://www.seeedstudio.com/PIR-Motion-sensor-m odule-p-74.html

PIR sensor is a motion detector sensor. PIR Sensor means Passive Infrared Sensor with two slots each one made up of IR sensor measure the infrared light radiating from objects when a warm body like human or animal passes through it the PIR sensor depicts the motion. They are commonly used in restricted areas to detect the motion for security purpose and they are also used in security alarms.

\section{SEQUENCE FLOW DIAGRAM:}

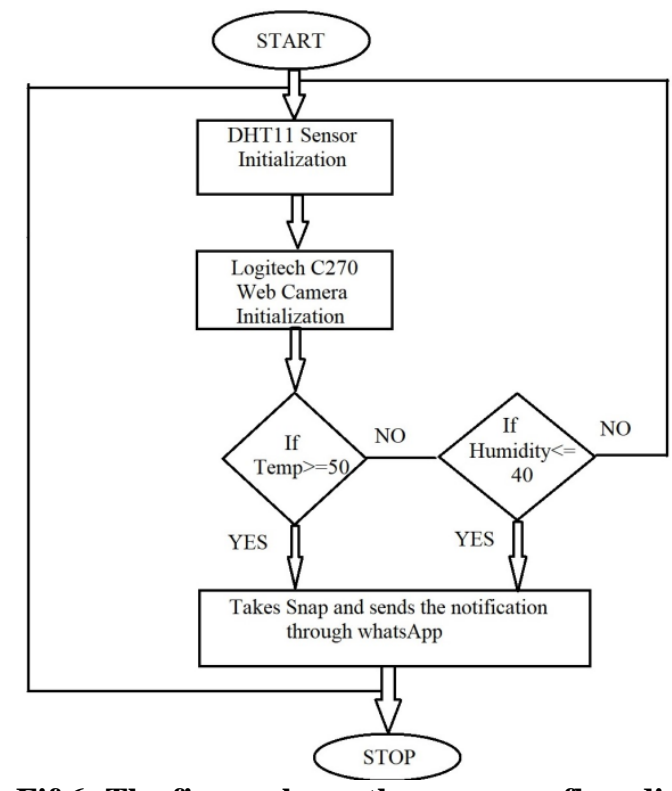

Fif.6: The figure shows the sequence flow diagram of DHT11 sensor working.

Table.1: Varying of pulse among temperature and humidity values.

\begin{tabular}{|l|c|c|c|}
\hline S. NO & $\begin{array}{c}\text { Temperature } \\
(\mathrm{T})\end{array}$ & $\begin{array}{c}\text { Humidity } \\
(\mathrm{H})\end{array}$ & $\mathrm{T} \| \mathrm{H}$ \\
\hline 1. & 0 & 0 & 0 \\
\hline 2. & 0 & 1 & 1 \\
\hline 3. & 1 & 0 & 1 \\
\hline 4. & 1 & 1 & 1 \\
\hline
\end{tabular}

At first, the DHT11 sensor and camera get initialized then it checks both the temperature and humidity if temperature greater than or equal to 50 degrees centigrade or humidity less than or equal to $40 \%$ or if both happens then takes the snap and sends the picture through WhatsApp to the user.

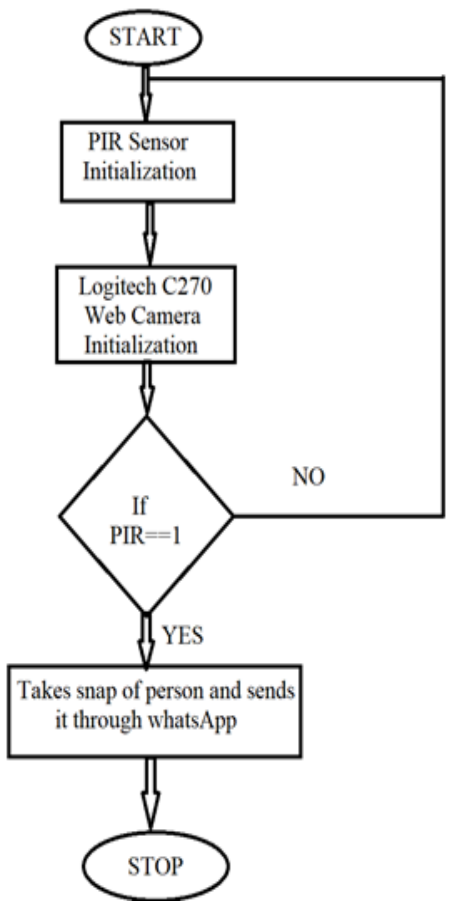

Fig.7 this figure shows the sequence flow diagram PIR sensor:

Initially, the PIR sensor and camera gets initialized.Later, the PIR sensor checks the motion and if the PIR sensor raises to high pulse, then the web camera takes the snap and sends the picture to the user through WhatsApp else process goes to the starting step and repeats continuously.

\section{RESULTS}

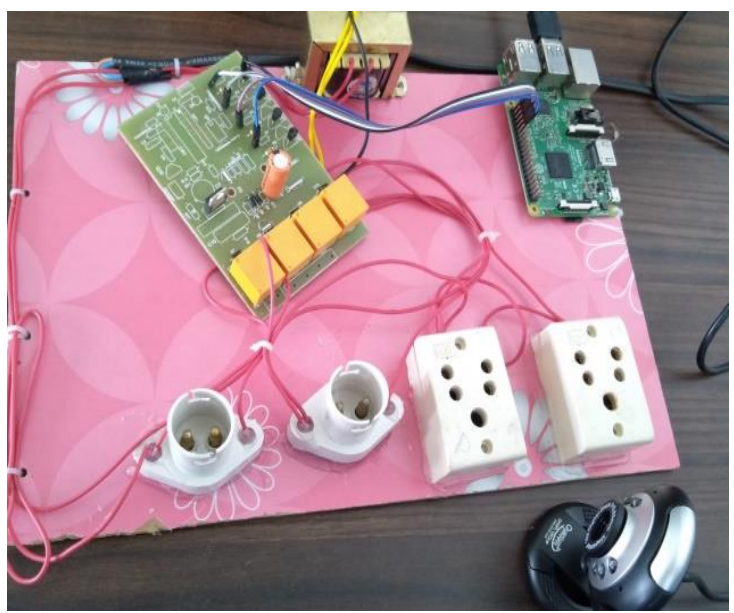

Fig.8: Hardware Implementation

This System is executed and the outcomes have been confirmed for all intents and purposes. It encourages the client to screen and control the home apparatuses associated through WhatsApp.

\section{Results are as follows:}

The outcomes have been acquired through ThingsSpeak. In the wake of marking into the ThingsSpeak account and creating the necessary fields, an API (Application Programming Interface) key has been produced and through this the can get the diagrams.

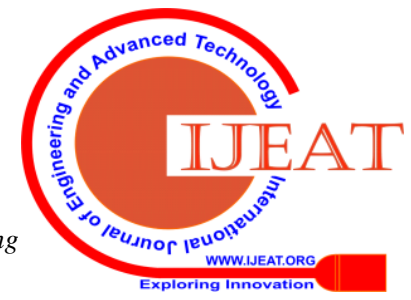




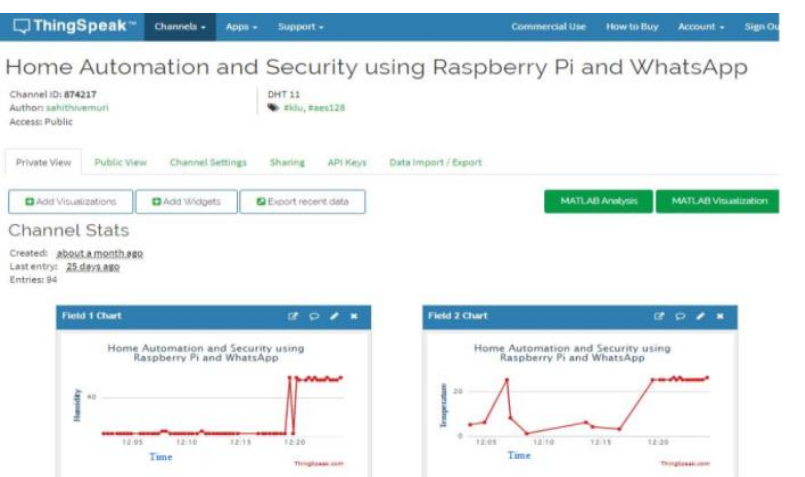

Fig.9: Graphs for both temperature and humidity

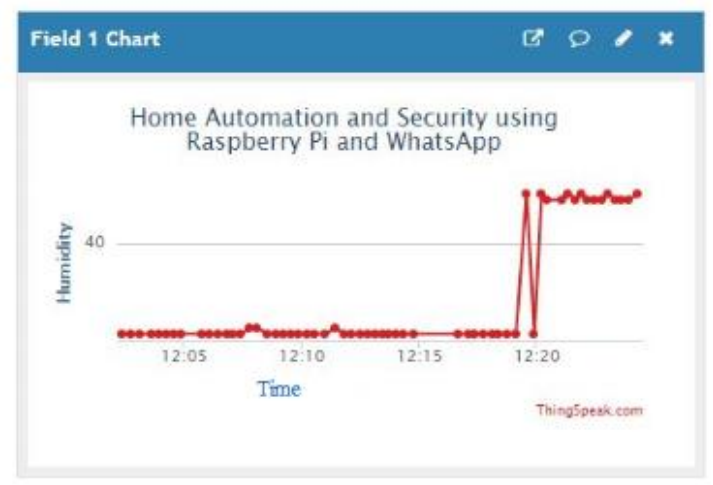

Fig.10: Graph for Humidity for certain period of time.

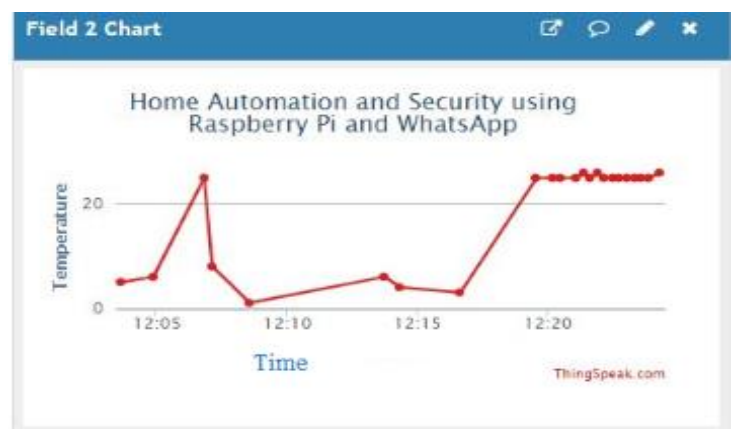

Fig.11: Graph for Temperature for certain period of time.

The ThingsSpeak has produced the data base for both temperature and humidity in .CSV format.

\begin{tabular}{|c|c|c|c|c|}
\hline$A$ & A & B & c & D \\
\hline 1 & created_at & entry_id & Humidity & Temperature \\
\hline 2 & 2019-10-12 05:59:36 UTC & 1 & 50 & 26 \\
\hline 3 & 2019-10-12 06:01:20 UTC & 2 & 49 & 25 \\
\hline 42 & 2019-10-12 06:01:36 UTC & 3 & 48 & 25 \\
\hline 5 & 2019-10-12 06:01:54 UTC & 4 & 49 & 26 \\
\hline 6 & 2019-10-12 06:02:15 UTC & 5 & 48 & 25 \\
\hline 72 & 2019-10-12 06:02:36 UTC & 6 & 49 & 26 \\
\hline 8 & 2019-10-12 06:02:52 UTC & 7 & 49 & 26 \\
\hline 9 & 2019-10-12 06:03:13 UTC & 8 & 49 & 26 \\
\hline 102 & 2019-10-12 06:03:36 UTC & 9 & 49 & 26 \\
\hline 112 & 2019-10-12 06:03:56 UTC & 10 & 49 & 26 \\
\hline 122 & 2019-10-12 06:04:21 UTC & 11 & 49 & 26 \\
\hline 132 & 2019-10-12 06:04:40 UTC & 12 & 49 & 26 \\
\hline 142 & 2019-10-12 06:05:00 UTC & 13 & 49 & 26 \\
\hline 15 & 2019-10-12 06:05:20 UTC & 14 & 49 & 26 \\
\hline 162 & 2019-10-12 06:05:39 UTC & 15 & 48 & 25 \\
\hline 172 & 2019-10-12 06:06:04 UTC & 16 & 48 & 25 \\
\hline 182 & 2019-10-12 06:06:25 UTC & 17 & 49 & 26 \\
\hline 19 & 2019-10-12 06:06:41 UTC & 18 & 49 & 26 \\
\hline 20 & 2019-10-12 06:07:11 UTC & 19 & 49 & 26 \\
\hline 212 & 2019-10-12 06:07:32 UTC & 20 & 49 & 26 \\
\hline 222 & 2019-10-12 06:07:55 UTC & 21 & 48 & 25 \\
\hline 23 & 2019-10-12 06:12:55 UTC & 22 & 49 & 26 \\
\hline 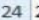 & 2019-10-12 06:15:17 UTC & 23 & 48 & 25 \\
\hline
\end{tabular}

Table.2: Database of both temperature and humidity with respect to tie.

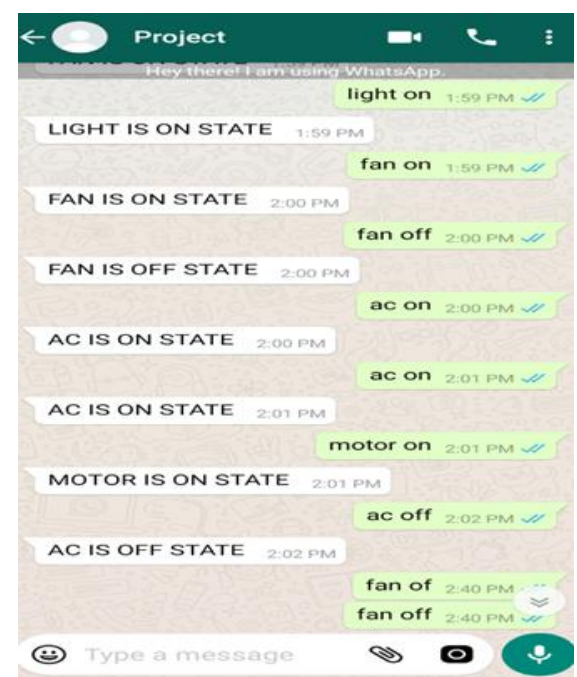

Fig.12: Obtaining messages from Raspberry $P i$.

\section{CONCLUSIONS}

In this automation world, due to overclocking and future expansion capabilities, Raspberry Pi has been proved to be an easy and economically efficient platform for implementing the home automation system and also in reducingthe human intervention. The current system supports efficient power usage, as well as, remote controlling of the home appliances.

\section{REFERENCES}

1. VineetPratap Singh, Prof. Urmila Deshmukh, Prof. Anjali M. Patki. "Facebook Based Home Appliances Security

2. Control and Monitoring Using Raspberry-PI 3",Vol. 5, Issue 5, May 2017. International Journal of Innovative Research in Computer

3. And Comlmunication Engineering.

4. 2.M. P. Sathish, Dr. S. A. K. Jilani, Mr. D. Girish Kumar "Home Automation through E-Mail using Raspberry Pi”, International Journal of Advanced Research in Electronics and Communication Engineering (IJARECE)

5. Volume 4, Issue 9, September 2015.

6. Vamsi Krishna Patchava, Hari BabuKandala,P Ravi Babu "A Smart Home Automation Technique with Raspberry Pi using IoT", 2015 International Conference on Smart Sensors and Systems (IC-SSS).

7. VikasKumawat, Shubham Jain, VikramVashisth, Neha Mittal, Bhupendra Kumar Jangir"Design of Controlling Home Appliance Remotely Using Raspberry pi”,2017 2nd International Conference for Convergence in Technology (I2CT).

8. YasirliAmri, MukhammadAndriSetiawan"Improving Smart Home Concept with the Internet of Things Concept Using Raspberry Pi and Node MCU",

9. K. Venkatesh, P. Rajkumar, S. Hemaswathi, B. Rajalingam "IoT Based Home Automation Using Raspberry Pi”, Jour of Adv Research in Dynamical \& Control Systems, Vol. 10, 07-Special Issue, 2018.

10. P Bhaskar Rao, S. K. Uma "Raspberry Pi Home Automation with Wireless Sensors using smart Phone", InternationalJournal of Computer Science and Mobile ComputingIJCSMC, Vol. 4, Issue. 5, May 2015, pg.797 - 803 ISSN 2320-088X

11. 8.Narayana M.V., Dusarlapudi K., Uday Kiran K., Sakthi Kumar B.,IoT based real time neonate monitoring system using arduino,2017 Journal of Advanced Research in Dynamical and Control Systems,Vol:9, issue:Special issue 14,pp: 1764-1772,DOI: ,ISSN: 1943023X.

12. 9.Madhav B.T.P., Sai Dheeraj G., Raghavarapu S.S. .," Design of a CPW-fed monopole antenna for ultrawide band based iot and medical applications “, 2018, International Journal of Engineering and Technology(UAE) ,Vol: 7 ,Issue: 2 ,pp: 9 to:: 12 ,DOI 11.14419/ijet.v7i2.31.13386 ,ISSN: 2227524X.

13. 10.Gopi Krishna P., Srinivasa Ravi K., Hareesh P., Ajay Kumar D., Sudhakar H. .," Implementation of bi-directional blue-fi gateway in IoT environment “, 2018, International Journal of Engineering and Technology(UAE) ,Vol: 7 ,Issue: ,pp: 733 to:: 738 ,DOI: ,ISSN 2227524X 
14. 11. BaburaoDhanade Y., Sreelakshmi K., Bora P., Mudliar M., Madhav B.T.P., Frequency reconfigurable dual band antenna for wireless communications, 2017 Journal of Advanced Research in Dynamical and Control Systems, Vol:9, issue: Special Issue 14, pp: 2328-2345, ISSN: 1943023X

\section{AUTHORS PROFILE}

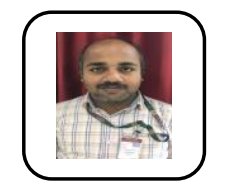

Mr.Pamarthi Kanakaraja, currently working as Assistant Professor in KLEF (Deemed to be University). He has 8 Years working experience On Embedded Designing \& Programming Concepts. He is Technical EMBEDDED DESIGNING concepts Adviser for many Engineering and Polytechnic (DIPLOMA) Students. He also published papers in various international journals. He is a Regular Contributor in EFY (Electronic for You) International Technical magazine. His area of research is Embedded Designing, Internet of Things (IOT) \& Artificial Intelligence (AI).

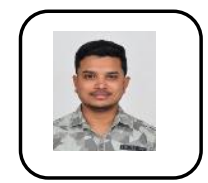

Mr.B Srikanth Deepak, is working as Assistant Professor in Dept. of Electronics and Communication Engineering at KoneruLakshmaiah Education Foundation. His Area of Work is Antennas and Communication Systems with 1 year Industrial (Project Trainee at DLRL, Hyd) Experience and 2.5 years of Academic Experience. His Current Research Work is on Fractal Antennas and Pattern Optimization.

K. V. Jaya Nikhil studyingB.Techin KoneruLakshmaiah Education FoundationDepartment of Electronics and Communication Engineering

Y. V. S Pavan Rakesh studying B.Tech inKoneruLakshmaiah Education FoundationDepartment of Electronics and Communication Engineering

K. Naga Venkatesh studying B.Tech inKoneruLakshmaiah Education Foundation,Department of .Electronics and Communication Engineering 